\title{
Importance of neutralizing antibody positivity in Turkish multiple sclerosis patients
}

\author{
Derya Kaya ${ }^{4 *}$, Serap Tufan ${ }^{2}$, Serkan Özakbaş ${ }^{3}$, Hakki Bahar $^{4}$, Emel Ada $^{5}$, Egemen İdiman ${ }^{2,3}$ \\ ${ }^{1}$ Department of Neurology, Ordu Public Hospital, Ordu, Turkey; ${ }^{*}$ Corresponding Author: deryakaya29@gmail.com \\ ${ }^{2}$ Neuroimmunology Laboratory, Faculty of Medicine, Dokuz Eylul University, Izmir, Turkey \\ ${ }^{3}$ Department of Neurology, Faculty of Medicine, Dokuz Eylul University, Izmir, Turkey \\ ${ }^{4}$ Department of Microbiology, Faculty of Medicine, Dokuz Eylul University, Izmir, Turkey \\ ${ }^{5}$ Department of Radiology, Faculty of Medicine, Dokuz Eylul University, Izmir, Turkey
}

Received 1 September 2013; revised 8 October 2013; accepted 21 October 2013

Copyright (C) 2013 Derya Kaya et al. This is an open access article distributed under the Creative Commons Attribution License, which permits unrestricted use, distribution, and reproduction in any medium, provided the original work is properly cited.

\section{ABSTRACT}

The frequency and the consequences of binding and neutralizing antibodies (BAbs and NAbs) against Interferon beta (IFNbeta) in Turkish multiple sclerosis (MS) patients have not been determined yet, which could differ in such a country which is between Europa and Asia. The aim of the study is to assess the frequency of these antibodies, and to evaluate the impact of NAbs, from the clinical and radiologic aspects in Turkish patients with MS. One hundred and two MS patients were included. BAbs were screened using capture enzyme-linked immunosorbent assay (cELISA), and NAbs were detected via Myxovirus protein A (MxA) messenger RNA (mRNA) induction assay (real-time polymerase chain reaction-PCR) at the beginning and one year later. Relapse rate and expanded disability status scale (EDSS) were used to assess the clinical impact. Gadolinium enhanced lesions and T2 lesion volume were used as magnetic resonance imaging (MRI) parameters. Persistent NAb positivity defines to be positive both at first and then one year later. NAbs were detected in $12.2 \%$ (6/49) of IFNbeta-1b treated patients, and in $7.5 \%$ (3/40) of IFNbeta-1a SC treated patients, but none of the IFNbeta-1a IM treated patients had detectable NAbs. It was found that the mean relapse rate difference was significantly higher in persistent NAb negative patients $(p=0.024)$. Persistent NAb positivity had no effect on T2 lesion volume and contrast enhancing lesions. $60 \%$ of the persistent NAb positive patients had at least one relapse during one-year of follow-up. On the other hand, $32 \%$ of persistent NAb nega- tive patients were detected to have at least one relapse. Data from this study suggest that patients may become unresponsive to IFNbeta therapy even when the frequency of NAbs does not prove to be as high as those in the literature. Nevertheless, one should keep in mind that disease activity is not always equal to NAb positivity.

Keywords: Interferon Beta; Multiple Sclerosis; Neutralizing Antibody

\section{INTRODUCTION}

Interferon beta (IFNbeta) is one of the first line of immune treatment options for multiple sclerosis (MS) for over 20 years. However, repeated IFNbeta injections may induce IFNbeta antibody production in some patients. Such antibodies are called binding antibodies (BAbs), which do not affect the biological activity of the molecule, and neutralizing antibodies (NAbs), which are associated with a decrease in the efficacy of the treatment $[1,2]$. In fact, NAbs are a subset of BAbs which prevent the binding of the IFN $\beta$ to its receptor on the surface of cells. When BAbs are detectable it is likely that NAbs are also present [3].

There are a large number of papers addressing neutralizing antibodies against IFNbeta from Europa and North America. Recently, a group from Japan reported that the prevalence of NAbs is similar to that in Caucasian populations and is associated with an increase in disease activity [4]. However, there is no information about Turkish MS patients' antibody status and their impacts. Neutralizing antibodies are not tested routinely in Turkey. When there is a need, the blood sample of the patient is sent to a center abroad. Mostly, in daily prac- 
tice, in patients doing poorly clinically, a switch to a non-IFNbeta therapy is initiated independent of NAb.

To our knowledge, this is the first study that assesses the frequency of the neutralizing antibodies and their effect on disease activity in Turkish MS patients. The frequency and the impact of NAbs could differ in our country which is located at the crossroads of Europe and Asia. From another point of view, it is important to reevaluate the treatment of those whose disease activity is higher due to NAb.

In the present study, the frequency of BAbs and NAbs, and impact of these antibodies, from the clinical and radiologic aspects in Turkish patients with MS were assessed.

\section{METHODS}

\subsection{Participants}

We included 274 consecutive MS patients between May 2008 and October 2009. All patients were routinely attending the Neurology Department of Dokuz Eylul University Hospital, Izmir. Patients were receiving one of three IFN-beta preparations: interferon b-1B ("Betaferon", Bayer) or interferon b-1A ("Rebif 44 mg", both Merck-Serono, or "Avonex", Biogen). Inclusion criteria required: a) a neurologist-confirmed diagnosis of definite relapsing-remitting MS according to the McDonald criteria [5]; b) age of $18-55$; c) to be already treated only with IFNbeta for at least 18 months; d) to be relapse-free for at least 30 days prior to testing. Exclusion criteria were: a) to receive immunosuppressive treatment within the preceding year; b) to receive intravenous immunoglobulin (IVIG) or plasmapheresis within the last six months; c) to have primary progressive MS; d) to have upper respiratory tract infection within three weeks; e) to receive corticosteroid treatment due to an attack within three months. The local University Hospital Medical Ethics Committee approved the research proposals for the study. Written informed consent was obtained from patients who participated in this study. A total of 102 patients were eligible for the study. Clinical characteristics of the 102 patients are shown in Table 1.

\subsection{Binding Antibody Analysis}

$2.5 \mathrm{ml}$ venous blood was drawn in serum tubes for $\mathrm{BAb}$ analysis, and samples were screened using capture enzyme-linked immunosorbent assay (cELISA) first at the time of study and later, the following year. Persistent $\mathrm{BAb}$-positivity indicates patients who were $\mathrm{BAb}$ positive both at their first and final assessments.

\subsection{Neutralizing Antibody Analysis}

Blood samples were collected in PAXgene tubes (Pre Analytix GmbH, Hombrechticon, CH) 12 - 14 hours af- ter an injection of IFN, and NAbs were detected via Myxovirus protein A (MxA) messenger RNA (mRNA) induction assay (real-time polymerase chain reactionPCR), first at the time of study and later, the following year.

RNA extraction and cDNA synthesis were done using commercially available kits (Preanalytix by Qiagen, and Superscript II Reverse Transcriptase, Invitrogen, Carlsbad, CA). PCR was performed on an ABI 7500 Fast Real Time PCR System (Applied Biosystems) using a commercially available TaqMan Universal PCR Master Mix and primer/probe kits. Gene expression in each sample of the target mRNA relative to GAPDH $(\Delta \mathrm{Ct})$ was compared to a calibrator consisting of pooled cDNA from healthy controls. A normalization ratio (NR) was calculated using the formula $\mathrm{NR}=2^{-\Delta \Delta \mathrm{Ct}}$, where $\Delta \Delta \mathrm{Ct}=$ $\Delta \mathrm{Ct}$ (sample) $-\Delta \mathrm{Ct}$ (pool). NR reflects fold induction of gene expression as compared to expression in the control pool. Samples were run in duplicate.

Persistent NAb-positivity indicates patients who were NAb positive both at their first and final assessments. Both binding and neutralizing antibody analyses were performed in the neuroimmunology laboratory of Faculty of Medicine of Dokuz Eylul University, Izmir.

\subsection{Clinical and Radiologic Evaluation}

A relapse was recorded only if the physician described new findings consistent with the patient's reported symptoms, and had excluded the possibility of a pseudorelapse. Relapse rate and Expanded Disability Status Scale (EDSS) [6] were used to assess the clinical impact.

Table 1. Demographical and clinical features of the patients.

\begin{tabular}{cc}
\hline & Patients \\
\hline Gender n (\%): & \\
Female & $68(66.7)$ \\
Male & $34(33.3)$ \\
Mean age ( \pm SD) (range) & $34.2 \pm 7.9(19-53)$ \\
& \\
Mean disease duration (year) ( \pm SD) (range) & $7.9 \pm 4.9(2-23)$ \\
Disease course: RRMS (n)/SPMS (n) & $98 / 4$ \\
Mean IFN $\beta$ treatment duration & \\
(month) ( \pm SD) (range) & \\
Mean relapse rate before IFN $\beta$ treatment & $1.1 \pm 0.6(0-3.5)$ \\
$( \pm$ SD) (range) & $\mathrm{n}(\%)$ \\
IFN $\beta$ preparation & $49(48)$ \\
IFN $\beta-1 \mathrm{~b}$ & $40(39.2)$ \\
IFN $\beta$-1a SC & $13(12.8)$ \\
IFN $\beta$-1a IM &
\end{tabular}

SD: standard deviation; RRMS: relapsing remitting multiple sclerosis; SPMS: secondary progressive multiple sclerosis; IFN $\beta$ : interferon beta; SC: subcutaneous; IM: intramuscular. 
EDSS scoring was performed at baseline and one year later. Also, number of relapses was recorded within one year of study.

Magnetic resonance imaging (MRI) scans were performed after blood sampling at the beginning and than one year later. Hyperintense lesions on T1-weighted postgadolinium sequences were counted. T2 lesion total volume was calculated within the proton density/T2 weighted images semi-automatically using "Lesion Annotation and Volume Assessment (LAVA) software, Medical Image Mining Laboratories (New York)" in Windows XP operating system on personal computers. All radiologic images were assessed by a blind radiologist.

\subsection{Statistical Analysis}

SPSS 15.0 for Windows was used for the statistical analysis. Descriptive features for continuous variables were implied as mean and standard deviation (SD), and for discontinuous variables as number and percent. The comparison of continuous variables between two independent groups was done with Mann-Whitney U test, and when more than two groups with Kruskal-Wallis test if the normal distrubition could not be fulfilled. Wilcoxon test was used for the time effect in between dependent groups due to lack of normal distrubition of the difference between continous variables. The significancy of $<0.05$ had been accepted.

\section{RESULTS}

Demographic and clinical characteristics were similar in three different treatment groups (Table 2).

\subsection{The First Evaluation}

BAbs were detected in $26.5 \%(27 / 102)$ of the patients. Of 49 patients treated with IFN $\beta-1 b, 40.8 \%$ were BAb positive at the beginning of our study, whereas of 40 patients treated with IFN $\beta$-1a SC, $15 \%$ were BAb positive; and of 13 patients treated with IFN $\beta$-1a IM, $7.7 \%$ were $\mathrm{BAb}$ positive. $\mathrm{BAb}$ positivity was higher in IFN $\beta-1 \mathrm{~b}$ treated group than IFN $\beta$-1a treated group, and in IFN $\beta$ 1a preparation, the patients treated with $\mathrm{SC}$ form had higher BAb positivity than IM form $(\mathrm{p}=0.006)$.

NAbs were detected in $8.8 \%(9 / 102)$ of all the patients. NAbs were present in $12.2 \%(6 / 49)$ of IFN $\beta-1 \mathrm{~b}$ treated patients, and in $7.5 \%(3 / 40)$ of IFN $\beta-1 \mathrm{a} \mathrm{SC}$ treated patients, but none of the IFN $\beta$-1a IM $(0 / 13)$ treated patients had detectable NAbs. The treatment duration was longer in NAb negative patients than in $\mathrm{NAb}$ positive patients, but it was not statistically significant (respectively 45.28 months; $\mathrm{p}=0.055$ ) (Table 3).

$98.7 \%$ of $\mathrm{BAb}$ negative patients were NAb negative, and $29.6 \%$ of $\mathrm{BAb}$ positive patients were $\mathrm{NAb}$ positive.
Table 2. Demographic and clinical characteristics of the three different treatment groups.

\begin{tabular}{|c|c|c|c|c|}
\hline & IFN $\beta-1 b$ & IFN $\beta$-1a SC & $\begin{array}{l}\text { IFN } \beta \text {-1a } \\
\text { IM }\end{array}$ & $\mathbf{p}^{*}$ \\
\hline & Mean \pm SD & Mean \pm SD & Mean \pm SD & \\
\hline Mean Age & $35.4 \pm 7.9$ & $33.8 \pm 8.0$ & $31.0 \pm 7.3$ & 0.210 \\
\hline $\begin{array}{c}\text { Mean Disease } \\
\text { Duration (y) }\end{array}$ & $8.7 \pm 5.6$ & $7.3 \pm 4.6$ & $6.9 \pm 2.2$ & 0.532 \\
\hline $\begin{array}{l}\text { Mean EDSS } \\
\text { before IFN } \beta\end{array}$ & $2.0 \pm 0.9$ & $2.2 \pm 1.2$ & $1.9 \pm 1.3$ & 0.627 \\
\hline $\begin{array}{l}\text { Mean EDSS in } \\
\text { the First } \\
\text { Evaluation }\end{array}$ & $2.0 \pm 1.1$ & $2.5 \pm 1.7$ & $1.7 \pm 1.0$ & 0.262 \\
\hline $\begin{array}{c}\text { Mean Relapse } \\
\text { Rate before IFN } \beta\end{array}$ & $1.2 \pm 0.6$ & $1.2 \pm 0.7$ & $1.0 \pm 0.4$ & 0.771 \\
\hline $\begin{array}{c}\text { Mean } \\
\text { Treatment } \\
\text { Duration }\end{array}$ & $41.2 \pm 26.0$ & $42.2 \pm 22.6$ & $56.2 \pm 24.4$ & 0.054 \\
\hline
\end{tabular}

y: year; IFN $\beta$ : interferon beta; m: month; ${ }^{*}$ Kruskal Wallis test.

There was only one NAb positive patient who was found to be $\mathrm{BAb}$ negative.

\subsection{The Second Evaluation}

Six of 102 patients dropped out one year after the first sampling time. $38.5 \%(n=37 / 96)$ of patients were BAb positive. The increase in BAb positivity during one year follow-up was statistically significant only in IFN $\beta$-1b treated patients (respectively $41 \%, 56 \% ; \mathrm{p}=0.039$ ). Persistent BAb positivity was found $25 \%(24 / 96)$.

In the second evaluation (one year later), NAb was present in $7.3(7 / 96)$ of all the patients. Similar to the first evaluation, none of the IFN $\beta$-1a IM treated patients had detectable NAbs. NAb had disappeared in three of the IFN $\beta-1 \mathrm{~b}$ treated NAb positive patients and in one of the IFN $\beta$-1a SC treated NAb positive patient, whereas $\mathrm{NAb}$ had appeared in two of the IFN $\beta-1 \mathrm{~b}$ SC treated $\mathrm{NAb}$ negative patients. Persistent NAb positivity was found $5.2 \%(5 / 96)$.

\subsection{Clinical Evaluation}

Neither BAb positivity in the first evaluation nor persistent BAb positivity had any effect on relapse rate and progression of disability in terms of EDSS scoring.

The mean relapse rate difference was significantly higher in persistent NAb negative patients than in persistent NAb positive patients $(\mathrm{p}=0.024)$ (Table 4). Mean EDSS change did not differ significantly between patients who were persistent $\mathrm{NAb}$ positive or NAb negative $(\mathrm{p}$ $=0.22$ ). $60 \%$ of the persistent NAb positive patients were detected to have at least one relapse, whereas it was 32\% of persistent $\mathrm{NAb}$ negative patients during one-year 
Table 3. Features of patients regarding to NAb status.

\begin{tabular}{|c|c|c|c|}
\hline & \multicolumn{2}{|c|}{$\mathrm{NAb}$} & \multirow[b]{2}{*}{$\mathbf{p}$} \\
\hline & negative & positive & \\
\hline Mean Age $( \pm \mathrm{SD})$ & $34.4 \pm 7.9$ & $32.9 \pm 6.1$ & 0.816 \\
\hline $\begin{array}{l}\text { Mean Disease Duration } \\
\text { (y) }( \pm \mathrm{SD})\end{array}$ & $8.3 \pm 5.1$ & $4.6 \pm 2.0$ & 0.050 \\
\hline $\begin{array}{l}\text { Mean IFN } \beta \text { Duration } \\
\quad(\mathrm{m})( \pm \mathrm{SD})\end{array}$ & $44.8 \pm 25.0$ & $28.1 \pm 10.1$ & 0.055 \\
\hline $\begin{array}{l}\text { Mean EDSS in the First } \\
\text { Evaluation }( \pm \text { SD })\end{array}$ & $2.1 \pm 1.4$ & $1.9 \pm 0.8$ & 0.835 \\
\hline $\begin{array}{l}\text { Mean Relapse Rate } \\
\text { before IFN } \beta( \pm \mathrm{SD})\end{array}$ & $1.1 \pm 0.6$ & $0.9 \pm 0.5$ & 0.205 \\
\hline
\end{tabular}

y: year; IFN $\beta$ : interferon beta; m: month.

of follow-up $(\mathrm{p}=0.330)$.

\subsection{Radiologic Evaluation}

It was shown that persistent NAb positivity had no effect on T2 lesion volume (Table 5) and contrast enhancing lesions in MRI (Table 6).

\section{DISCUSSION}

In the literature, it was reported that $28 \%-47 \%$ of IFN $\beta-1 \mathrm{~b}$ treated patients, $12 \%-28 \%$ of IFN $\beta-1 \mathrm{a}$ SC treated patients, and $2 \%-6 \%$ of IFN $\beta$-1a IM treated patients had developed NAbs [7-13]. In our study, NAbs were present in $12.2 \%$ of IFN $\beta-1 \mathrm{~b}$ treated patients, and in $7.5 \%$ of IFN $\beta-1 \mathrm{a}$ SC treated patients, but none of the IFN $\beta$-1a IM treated patients had detectable NAbs. The frequency of persistent $\mathrm{NAb}$ positive patients was also lower when compared to other similar studies [14-16], which might be due to genetic features of Turkish MS patients. Another possible explanation for the low proportion of persistent NAb positive patients could be about mean IFNbeta treatment duration. It was roughly 3.6 years in the present study. Several studies showed that $40 \%$ of patients treated with IFNb-1b reverted to NAb negative status within 4 years [17]. So that, some of our NAb positive patients could have reverted to NAb negative before the study. Three NAb positive patients receiving IFNbeta- $1 \mathrm{~b}$ and one NAb positive patient receiving IFNbeta-1a reverted to NAb negative status even in one year time in our study. Consistent with the results to other studies, IFN $\beta$-1b was found more immunogenic than IFN $\beta$-1a SC, and IFN $\beta$-1a SC was more immunogenic than IFN $\beta$-1a IM $[9,18]$.

Patients whose IFNbeta treatmet duration was at least 18 months were included in the present study. The reasons for that were, firstly, NAb appear between 3 to 18 months after the treatment [19], and secondly, determining persistence of NAbs does not seem to be reliable
Table 4. The mean relapse rate difference between persistent $\mathrm{NAb}$ positive and negative patients.

\begin{tabular}{ccccc}
\hline & & $\begin{array}{c}\text { Before IFN } \boldsymbol{\beta} \\
\text { Therapy }\end{array}$ & $\begin{array}{c}\text { After IFN } \boldsymbol{\beta} \\
\text { Therapy }\end{array}$ & \\
\hline NAb & Mean \pm SD & Mean \pm SD & $\mathbf{p}^{*}$ \\
\hline $\begin{array}{c}\text { Relapse } \\
\text { Rate }\end{array}$ & PP $(\mathrm{n}=5)$ & $1.00 \pm 0.35$ & $0.60 \pm 0.55$ & 0.34 \\
& $\mathrm{PN}(\mathrm{n}=85)$ & $1.57 \pm 0.80$ & $0.28 \pm 0.40$ & $<0.001$ \\
$\begin{array}{c}\text { Difference } \\
\text { in Relapse } \\
\text { Rate }\end{array}$ & $\mathrm{PP}(\mathrm{n}=5)$ & $-0.40 \pm 0.82$ & \\
& $\mathrm{PN}(\mathrm{n}=85)$ & $-1.37 \pm 0.85$ & \\
\hline
\end{tabular}

IFN $\beta$ : interferon beta; Nab: neutralizing antibodies; PP: persistent positive PN: persistent negative; "Wilcoxson Test; ${ }^{* *}$ Mann Whitney U Test.

Table 5. Mean difference in T2 lesion total volume between persistent $\mathrm{NAb}$ positive and negative patients.

\begin{tabular}{lcccc}
\hline \multicolumn{5}{c}{ First Evaluation Second Evaluation } \\
\hline & NAb & Mean \pm SD & Mean \pm SD & $\mathbf{p}^{*}$ \\
\hline $\begin{array}{c}\text { T2 Lesion } \\
\text { Volume }\end{array}$ & PP $(\mathrm{n}=5)$ & $3.67 \pm 0.51$ & $2.83 \pm 0.66$ & 0.18 \\
& PN $(\mathrm{n}=85)$ & $8.59 \pm 11.04$ & $9.41 \pm 11.91$ & $\mathbf{0 . 0 2}$ \\
$\begin{array}{c}\text { T2 Lesion } \\
\text { Volume } \\
\text { Difference }\end{array}$ & PP $(\mathrm{n}=5)$ & $-0.83 \pm 0.15$ & \\
& PN (n=85) & & \\
& $\mathbf{p}^{* *}$ & $0.82 \pm 2.24$ & \\
\hline
\end{tabular}

NAb: neutralizing antibodies; PP: persistent positive; PN: persistent negative; SD: standard deviation; "Wilcoxson Test; ${ }^{* *}$ Mann Whitney U Test.

Table 6. Mean difference in CELs between persistent NAb positive and negative patients.

\begin{tabular}{ccccc}
\hline & & $\begin{array}{c}\text { First } \\
\text { Evaluation }\end{array}$ & $\begin{array}{c}\text { Second } \\
\text { Evaluation }\end{array}$ & \\
\hline & NAb & Mean \pm SD & Mean \pm SD & $\mathbf{p}^{*}$ \\
\hline CELs & PP $(\mathrm{n}=5)$ & $0.50 \pm 0.71$ & $1.50 \pm 2.12$ & 0.31 \\
& PN $(\mathrm{n}=85)$ & $0.17 \pm 0.79$ & $0.33 \pm 1.00$ & 0.32 \\
CELs & PP $(\mathrm{n}=5)$ & $1.00 \pm 1.41$ & \\
Difference & PN $(\mathrm{n}=85)$ & \multicolumn{2}{c}{$0.16 \pm 1.22$} \\
& $\mathbf{p}^{* *}$ & & 0.17 & \\
\hline
\end{tabular}

CELs: contrast enhancing lesions; Nab: neutralizing antibodies; PP: persistent positive; PN: persistent negative; SD: standard deviation; "Wilcoxson Test; ${ }^{* *}$ Mann Whitney U Test.

before month $12-18$ on treatment $[20,21]$ and finally, it was shown that NAbs against IFNbeta were characterized by low affinity antibodies in the first $6-12$ months that have a protective effect on IFNbeta and hence increase the effect of IFNbeta [22]. 
There are a number of methods that have been developed to detect NAbs. Antiviral assays (AVA) in which IFN- $\beta$ inhibits viral replication have been commonly used [17]. Another approach for measuring NAbs is the myxovirus resistance protein $\mathrm{A}(\mathrm{MxA})$ induction assay, which measures the expression of the IFN-inducible GTPase MxA in cultured cells [23]. A reporter gene assay has been developed [24,25]. Recently, a new noncell-based NAb assay has been described [26]. Besides, there is still ongoing researches for the development of a reliable, quick, standard and cost-effective NAb assay. In our study, NAbs are not detected using functional assays of interferon-responsive cell lines in culture, beacuse cell cultures are not feasible for our laboratory condition. Alternatively, NAbs were detected via MxA mRNA induction assay. It was shown that treatment of patients with IFNbeta leads to maximal MxA increase at about 12 $\mathrm{h}$ post injection [27]. Following treatment of the patient with IFNbeta at $12-14 \mathrm{~h}$, we collected blood samples into special tubes designed to lyse the cells and stabilize the mRNA. The mRNA is extracted, converted to cDNA by reverse transcription and analyzed by real-time PCR. If the patient has NAbs to IFN $\beta$ the amount of MxA produced is reduced or, in the case of particularly high NAb titres, abolished [27-29].

It was shown that BAb positivity precedes the development of NAbs and BAb positivity appears to be a predictor of subsequent NAb development [30,31]. Regarding this, we found that $98.7 \%$ of $\mathrm{BAb}$ negative patients were NAb negative. As studies focused on the standardization and detecting techniques of NAb analyses [16,28, 32-35], importance of BAb anaysis, which is cheaper and less time consuming, has been neglected. We think that if there are patients doing poorly clinically that are considered due to NAbs, BAb analysis using ELISA could be used as a first step. When BAb is negative, it is most likely that the reason is not NAb. In relation to this, a recent paper also suggest to use ELISA measurements of BAbs to identify patients with high titres of NAbs, and in patients with low titres, they suggest to supplement ELISA with measurement of MX1 mRNA to establish whether the bioavailability of IFN-b is preserved [36].

During one-year of follow up, $60 \%$ of the persistent $\mathrm{NAb}$ positive patients had at least one relapse; this finding can be significant even for a clinically stable NAb positive patient and she/he should be followed up more closely. On the other hand, $32 \%$ of persistent NAb negative patients were detected to have relapses which may be due to mechanisms by non-NAb mediated molecules [31]. This finding could also reinforce that NAbs account for only a minor part of breakthrough disease [37].

The only parameter that NAb was shown to be associated with a decline in therapeutic effects was relapse rate. We found that NAb positive patients had a higher relapse rate. Our study failed to demonstrate significant impact of NAbs on progression of disability and MRI measures of disease activity. This lack of effect on MRI parameters may be due to small number of persistent NAb positive patients.

The main limitation of this study relates to the number of patients in the study. It was mostly due to our study population included those who were treated only with IFNbeta for at least 18 months from one center. Therefore, a confirmation prospective multicenter study with a large number of MS patients would help to prove the real power of NAbs. Moreover, our study is a short-term one. The evaluation of the impact of NAbs on MS disease progression requires long-term studies in large cohorts of IFNb-treated MS patients.

\section{CONCLUSION}

From a clinical point of view, reliably identifying NAb positive and NAb negative patients is crucial for the development of a new treatment algorithm for the patient. The present study observation reinforces the importance of NAb on relapse rate and shows that patients may become unresponsive to IFNbeta therapy even when the frequency of NAbs does not prove to be as high as those in the literature. Nevertheless, further studies with a larger number of Turkish MS patients should examine to confirm our clinical results.

\section{REFERENCES}

[1] Chou Bellomi, F., Scagnolari, C., Tomassini, V., Gasperini, C., Paolillo, A. and Pozzilli, C. (2003) Fate of neutralizing and binding antibodies to IFN beta in MS patients treated with IFN beta for 6 years. Journal of Neurological Sciences, 215, 3-8.

http://dx.doi.org/10.1016/S0022-510X(03)00173-4

[2] Deisenhammer, F., Schellekens, H. and Bertolotto, A. (2004) Measurement of neutralizing antibodies to interferon beta in patients with multiple sclerosis. Journal of Neurology, 215, 1131-1139.

[3] Bendtzen, K. (2003) Anti-IFN BAb and NAb antibodies: A minireview. Neurology, 61, 6-10. http://dx.doi.org/10.1212/01.WNL.0000092357.07278.09

[4] Sato, D.K., Nakashima, I., Fukazawa, T., Shimizu, Y., Tomizawa, Y. and Yokoyama, K. (2012) Neutralizing antibodies are associated with a reduction of interferon- $\beta$ efficacy during the treatment of Japanese multiple sclerosis patients. The Tohoku Journal of Experimental Medicine, 228, 85-92. http://dx.doi.org/10.1620/tjem.228.85

[5] McDonald, W.I., Compston, A., Edan, G., Goodkin, D., Hartung, H.P. and Lublin, F.D. (2001) Recommended diagnostic criteria for MS: Guidelines from the international panel on the diagnosis of MS. Annuals of Neurology, 50, 121-127. http://dx.doi.org/10.1002/ana.1032

[6] Kurtzke, J.F. (1983) Rating neurologic impairment in 
multiple sclerosis: An expanded status scale (EDSS). Neurology, 33, 1444-1452.

http://dx.doi.org/10.1212/WNL.33.11.1444

[7] Polman, C.H., Kappos, L., White, R., Dahlke, F., Beckmann, K. and Pozzilli, C. (2003) European study group in interferon beta-1b in secondary progressive MS: Neutralizing antibodies during treatment of secondary progressive MS with interferon beta-1b. Neurology, 60, 37-43. http://dx.doi.org/10.1212/WNL.60.1.37

[8] Kappos, L., Clanet, M., Sandberg-Wollheim, M., Radue, E.W., Hartung, H.P. and Hohlfeld, R. (2005) Neutralizing antibodies and efficacy of interferon $\beta$-1a: A 4-year controlled study. Neurology, 65, 40-47.

http://dx.doi.org/10.1212/01.wnl.0000171747.59767.5c

[9] Perini, P., Clabrese, M., Biasi, G. and Gallo, P. (2004) The clinical impact of interferon beta antibodies in relapsing-remitting MS. Journal of Neurology, 251, 305-309. http://dx.doi.org/10.1007/s00415-004-0312-8

[10] Kivisakk, P., Alm, G.V., Tian, W.Z., Matusevicius, D., Fredrikson, S. and Link, H. (1997) Neutralizing and binding anti-interferon- $\beta$ - $1 \mathrm{~b}$ (IFN- $\beta$-1b) antibodies during IFN$\beta$-1b treatment of multiple sclerosis. Multiple Sclerosis, $\mathbf{3}$, 184-190. http://dx.doi.org/10.1177/135245859700300303

[11] Sorensen, P.S., Ross, C., Clemmesen, K.M., Bendtzen, K., Frederiksen, J.L. and Jensen, K. (2003) Clinical importance of neutralising antibodies against interferon beta in patients with relapsing-remitting multiple sclerosis. Lancet, 362, 1184-1191. http://dx.doi.org/10.1016/S0140-6736(03)14541-2

[12] PRISMS (Prevention of Relapses and Disability by Interferon $\beta$-1a Subcutaneously in Multiple Sclerosis) Study Group (1998) Randomised double-blind plasebo controlled study of interferon $\beta$-1a in relapsing/remitting multiple sclerosis. Lancet, 352, 1498-1504. http://dx.doi.org/10.1016/S0140-6736(98)03334-0

[13] IFN $\beta$ Multiple Sclerosis Study Group, University of British Colombia MS/MRI Analysis Group (1996) Neutralizing antibodies during treatment of multiple sclerosis with interferon beta-1b: Experience during the first three years. Neurology, 47, 889-894.

[14] Pachner, A.R., Cadavid, D., Wolansky, L. and Skurnick, J. (2009) Effect of anti-IFN $\beta$ antibodies on MRI lesions of MS patients in the BECOME study. Neurology, 73, 14851492. http://dx.doi.org/10.1212/WNL.0b013e3181bf9919

[15] Pachner, A.R., Dail, D., Pak, E. and Narayan, K. (2005) The importance of measuring IFNbeta bioactivity: Monitoring in MS patients and the effect of anti-IFNbeta antibodies. Journal of Neuroimmunology, 166, 180-188. http://dx.doi.org/10.1016/j.jneuroim.2005.06.003

[16] Aarskog, N.K., Marøy, T., Myhr, K.M. and Vedeler, C.A. (2009) Antibodies against interferon-beta in multiple sclerosis. Journal of Neuroimmunology, 212, 148-150. http://dx.doi.org/10.1016/j.jneuroim.2009.04.012

[17] Sørensen, P.S., Koch-Henriksen, N., Ross, C., Clemmesen, K.M. and Bendtzen K. (2005) Appearance and disappearance of neutralizing antibodies during interferon-beta therapy. Neurology, 65, 33-39. http://dx.doi.org/10.1212/01.WNL.0000166049.51502.6 A
[18] Malucchi, S., Sala, A. and Gilli, F. (2004) Neutralizing antibodies reduce the efficacy of IFN during treatment of multiple sclerosis. Neurology, 62, 2031-2037. http://dx.doi.org/10.1212/01.WNL.0000129265.73259.9E

[19] Bertolotto, A., Malucchi, S., Sala, A., Orefice, G., Carrieri, P.B. and Capobianco, M. (2002) Differential effects of three interferon betas on neutralising antibodies in patients with multiple sclerosis. A follow up study in an independent laboratory. Journal of Neurology Neurosurgery Psychiatry, 73, 148-153. http://dx.doi.org/10.1136/jnnp.73.2.148

[20] Hartung, H.P., Munschauer, F. and Schellekens, H. (2005) Significance of neutralizing antibodies to interferon beta during treatment of multiple sclerosis: Expert opinions based on the proceedings of an international consensus conference. European Journal of Neurology, 12, 588-601. http://dx.doi.org/10.1111/j.1468-1331.2005.01104.x

[21] Polman, C.H., Bertolotto, A., Deisenhammer, F., Giovannoni, G., Hartung, H.P. and Hemmer, B. (2010) Recommendations for clinical use of data on neutralising antibodies to interferon-beta therapy in multiple sclerosis. Lancet Neurology, 9, 740-750. http://dx.doi.org/10.1016/S1474-4422(10)70103-4

[22] Sørensen, P.S., Koch-Henriksen, N. and Bendtzen, K. (2007) Are ex vivo neutralising antibodies against IFN-beta always detrimental to therapeutic efficacy in multiple sclerosis? Multiple Sclerosis, 13, 616-621. http://dx.doi.org/10.1177/1352458506072344

[23] Pungor Jr., E., Files, J.G., Gabe, J.D., Do, L.T., Foley, W.P. and Gray, J.L. (1998) A novel bioassay for the determination of neutralizing antibodies to IFN- $\beta 1$ b. Journal of Interferon Cytokine Research, 18, 1025-1030. http://dx.doi.org/10.1089/jir.1998.18.1025

[24] Farrell, R., Kapoor, R., Leary, S., Rudge, P., Thompson, A. and Miller, D. (2008) Neutralizing anti-interferon beta antibodies are associated with reduced side effects and delayed impact on efficacy of Interferon-beta. Multiple Sclerosis, 14, 212-218. http://dx.doi.org/10.1177/1352458507082066

[25] Lam, R., Farrell, R., Aziz, T., Gibbs, E., Giovannoni, G. and Grossberg, S. (2008) Validating parameters of a luciferase reporter gene assay to measure neutralizing antibodies to IFNbeta in multiple sclerosis patients. Journal of Immunological Methods, 336, 113-118. http://dx.doi.org/10.1016/j.jim.2008.03.014

[26] Cludts, I., Meager, A., Thorpe, R. and Wadhwa, M. (2013) Development and characterization of a non-cell-based assay to assess the presence of neutralizing antibodies to interferon-beta in clinical samples. Journal of Immunological Methods, 395, 37-44. http://dx.doi.org/10.1016/j.jim.2013.06.008

[27] Bertolotto, A., Gilli, F., Sala, A., Capobianco, M., Malucchi, S. and Milano, E. (2003) Persistent neutralizing antibodies abolish the interferon $\beta$ bioavailability in MS patients. Neurology, 60, 634-639. http://dx.doi.org/10.1212/01.WNL.0000046662.03894.C5

[28] Hesse, D., Sellebjerg, F. and Sorensen, S.P. (2009) Absence of MxA induction by interferon in patients with MS reflects complete loss of bioactivity. Neurology, 73, 372- 


\section{7. http://dx.doi.org/10.1212/WNL.0b013e3181b04c98}

[29] Malucchi, S., Gilli, F., Caldano, M., Sala, A., Capobianco, M. and Di Sapio, A. (2011) One-year evaluation of factors affecting the biological activity of interferon beta in multiple sclerosis patients. Journal of Neurology, 258, 895-903. http://dx.doi.org/10.1007/s00415-010-5844-5

[30] Pachner, A.R., Brady, J., Steiner, I. and Narayan, K. (2008) Management of neutralizing antibodies against beta-IFN in beta-IFN-treated multiple sclerosis patients. Journal of Neurology, 255, 1815-1817. http://dx.doi.org/10.1007/s00415-008-0854-2

[31] Gilli, F., Marnetto, F., Caldano, M., Valentino, P., Granieri, L. and Di Sapio, A. (2007). Anti-interferon-beta neutralising activity is not entirely mediated by antibodies. Journal of Neuroimmunology, 192, 198-205. http://dx.doi.org/10.1016/j.jneuroim.2007.09.025

[32] Pachner, A.R., Bertolotto, A. and Deisenhammer, F. (2003) Measurement of MxA mRNA or protein as a biomarker of IFN[beta] bioactivity: Detection of antibody-mediated decreased bioactivity (ADB). Neurology, 61, 24-26. http://dx.doi.org/10.1212/01.WNL.0000092361.04511.D0

[33] Bertolotto, A., Gilli, F. and Sala, A. (2001) Evaluation of bioavailability of three types of IFNb in multiple sclerosis patients by a new quantitative-competitive-PCR method for MxA quantification. Journal of Immunological Me- thods, 256, 141-152. http://dx.doi.org/10.1016/S0022-1759(01)00434-3

[34] Bertolotto, A., Sala, A., Caldano, M., Capobianco, M., Malucchi, S. and Marnetto, F. (2007) Development and validation of a real time PCR-based bioassay for quantification of neutralizing antibodies against human interferon-beta. Journal of Immunological Methods, 321, 1931. http://dx.doi.org/10.1016/j.jim.2006.12.012

[35] Gilli, F., Marnetto, F., Stefanuto, G., Rinaldi, V., Farinazzo, F. and Malucchi, S. (2004) Comparison of three PCR assays for the evaluation of interferon-beta biological activity in patients with multiple sclerosis. Journal of Molecular Diagnosis, 8, 185-194. http://dx.doi.org/10.1007/BF03260063

[36] Jensen, P.E.H., Sellebjerg, F., Søndergaard, H.B. and Sørensen, P.S. (2012) Correlation between anti-interferon-b binding and neutralizing antibodies in interferon-b-treated multiple sclerosis patients. European Journal of Neurolology, 19, 1311-1317. http://dx.doi.org/10.1111/j.1468-1331.2012.03721.x

[37] Sørensen, P.S. (2012) Effects of neutralizing antibodies to interferon beta in multiple sclerosis: A logical paradox. Multiple Sclerosis, 18, 131-132. http://dx.doi.org/10.1177/1352458511419438 